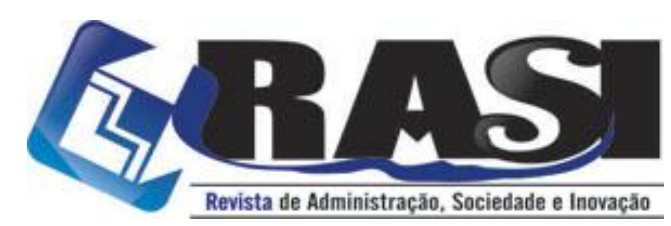

http://www.rasi.uff.br

RASI, Volta Redonda/RJ, v. 5, n. 1, pp. 91-109, jan./abr. 2019

\title{
Gestão e Improvisação em um Festival Cultural na Bahia
}

Fernanda Paquelet Moreira Barbosa (UFBA) - fpaquelet@gmail.com

Eduardo Davel (UFBA) - davel.eduardo@gmail.com

\section{RESUMO}

Os objetivos deste caso para ensino é suscitar aprendizagem sobre: (a) a importância crucial da improvisação para as organizações e gestores contemporâneos; (b) o papel da imperfeição, cooperação e competição para a prática da improvisação organizacional e (c) os desafios e competências de improvisação para gestores. O caso para ensino foi construído a partir de uma pesquisa empírica com base em informações oriundas de observação participante, prolongada e sistemática do processo de organização e gestão em vários eventos culturais na Bahia. O caso retrata o choque de estudantes de administração ao trabalhar em um megafestival cultural em Salvador. Descobrem, constatam e aprendem o quão estratégica a improvisação organizacional é para a gestão das organizações contemporâneas.

PALAVRAS-CHAVE: Improvisação Organizacional. Competência. Aprendizagem. Gestão de eventos. Festival Cultural.

\section{Management and Organizational Improvisation in a Cultural Festival in Bahia}

\section{ABSTRACT}

The goals of this teaching case are provoke learning about: (a) the crucial importance of improvising for contemporary organizations and managers, (b) the role of imperfection, cooperation and competition for organizational improvisation practice, and (c) improvisation challenges and competences for managers. The teaching case was built from an empirical research based on participant, broad and systematic observation of organizing and managing activities in several cultural events in Bahia. The case presents the chock of management students when they work in a mega cultural festival in Salvador. They discover, realize and learn how strategic is the organizational improvisation for managing contemporary organizations.

KEYWORDS: Organizational improvisation. Competency. Learning. Event management.

\begin{tabular}{c}
\hline $\begin{array}{c}\text { Universidade } \\
\text { Federal } \\
\text { Fluminense } \\
\text { R. Desembargador Ellis Hermydio Figueira, 783, Bloco A, sl. 218, Aterrado. } \\
27213-415 \text { - Volta Redonda, RJ - Brasil } \\
\text { www.uff.br }\end{array}$ \\
\hline $\begin{array}{c}\text { Copyright (c) 2019 RASI. Todos os direitos, até mesmo de tradução, são reservados. É } \\
\text { permitido citar parte de artigos sem autorização prévia, desde que seja identificada a fonte }\end{array}$ \\
\hline
\end{tabular}




\section{Gestão e Improvisação em um Festival Cultural na Bahia}

\section{Caso para Ensino}

\subsection{O Festival, a Empresa e os Estagiários}

A Contente Comunicação (CoC) é a empresa criadora e gestora do Festival Pleno Verão (FPVerão) que já está em sua vigésima quinta edição em Salvador (Bahia). Este Festival é caracterizado por acontecer, durante um mês, atividades artísticas em diversos pontos da cidade. São atividades de grande porte, com shows para 50 mil pessoas, e também apresentações de pequeno porte, para públicos restritos de 60 a 200 pessoas por sessão, como espetáculos de teatro, dança, música e circo. Um festival para toda a cidade.

Para a realização da vigésima quinta edição do FPVerão, vem à tona o desejo de renovação, de trazer pessoas novas. A CoC conta com 18 funcionários fixos e mais de 200 contratações diretas para o festival. Algumas ideias surgiram. Uma das mais aplaudidas foi a de trazer jovens para trabalhar dentro da empresa. Seriam dois jovens oriundos da universidade e um de projeto social, sendo todos maiores de idade.

Foram recebidos três estudantes: uma universitária do curso de Administração, um universitário do curso de Teatro e uma estudante secundarista. Esta faz parte de um projeto social onde está matriculada em uma turma de produção cultural. Na realização do FPVerão, eles serão responsáveis pela apresentação da banda Cantos do Destino no Palco do Rock.

Ana é a estudante de administração e já teve a oportunidade de acompanhar algumas produções de teatro quando ajudava seu namorado que atuava como ator. Essa ajuda acontecia durante as vésperas de estreia, quando precisavam resolver muitas coisas ao mesmo tempo, como ficar na bilheteria ou na portaria nos dias de apresentação de espetáculo. Ana é a mais experiente dos três estudantes.

Raimundo realiza sua segunda graduação. É estudante de teatro e está em um momento de decisão. Não sabe se vai abraçar o ofício de ator como profissão ou se vai continuar trabalhando como enfermeiro no hospital particular onde já está há dez anos.

Geralda acabou de completar dezoito anos e está estudando produção cultural na ONG 'Vamos Juntos', situada em seu bairro. Ela conseguiu essa vaga porque se destacou na prova de português. Ficou animada quando percebeu que era uma oportunidade desejada por muitos colegas e que tinha uma possibilidade de obter alguma experiência para além do seu bairro. Mas, não sabia exatamente o que significava fazer uma produção.

\subsection{O Primeiro Contato}

O salão de eventos no Hotel Fera era um pouco maior que uma sala de aula convencional. Estava com cadeiras dispostas em círculo. Uma távola redonda. As pessoas chegavam e sentavam na cadeira que quisessem. Algumas pessoas já se conheciam e sentavam próximas, umas das outras. Outras estavam completamente deslocadas. Às 8:00, Antônio começou a falar.

ANTÔNIO - É com muita felicidade que dou início a nossa reunião. Dentro de dois meses, iniciaremos as oficinas artísticas que antecedem as apresentações do Festival Pleno Verão. Por causa disso, nossa equipe aumentou. Para os 12 novos integrantes, que aqui estão, eu gostaria de dizer que a $\mathrm{CoC}$ possui um time incansável de 18 pessoas. Essas pessoas estão aqui e vão ajudar em tudo o que precisarem. No entanto, é preciso que entendam um princípio de nossa organização. Valorizamos muito a iniciativa na resolução de problemas. Sempre teremos metas 
bem definidas e objetivos claros. Mas, os caminhos para alcançá-los devem ser descobertos ou criados. Valorizamos o trabalho coletivo em total simbiose com o crescimento individual. Estou nessa empresa há 27 anos. A cada ano, desde que ela foi criada, vejo que acertamos em adotar uma política de desenvolvimento da empresa junto com o desenvolvimento dos colaboradores. Esse é o momento de nos conhecermos a todos. Cada um diz seu nome e que função exerce. Depois vamos conhecer melhor a história do festival e um pouco do que aconteceu ao longo de sua trajetória.

Foram 45 minutos nesse primeiro encontro. Em seguida, todos tomaram um café e passaram para outro salão onde tinham 6 mesas redondas e várias cadeiras confortáveis. Em cada mesa tinha uma garrafa de água, uma de café, copos, guardanapo, papel, canetas e um envelope com os nomes de todos que estavam destinados para aquela mesa. Dessa forma, Raimundo, Ana e Geralda se aproximaram mais. O envelope só poderia ser aberto quando todos da mesa estivessem acomodados.

No envelope, estavam seus nomes e de mais ninguém. Quando se apresentaram ao grupo, os três declararam pouca experiência. Eram os únicos em uma missão importante. O que estava acontecendo? A missão era de produzir a apresentação da Banda Cantos do Destino no Palco do Rock dentro da programação do primeiro dia do FPVerão onde aconteceriam 8 ações, ao mesmo tempo. Este palco - considerado de médio porte - atende um publico de 3 mil pessoas.

ANA - Me deu um frio na barriga.

RAIMUNDO - Eu estou achando maravilhoso.

GERALDA - Eu ainda não entendi muito bem o que a gente tem que fazer.

RAIMUNDO - Vai Ana, continua lendo.

ANA - "A Banda Cantos do Destino tem uma trajetória de sucesso no Brasil e será apresentada no Palco do Rock. Esse palco foi construído há 15 anos pela $\mathrm{CoC}$ e é utilizado para outras produções durante o ano. Fica na Praça da Cidade".

GERALDA - Onde fica a Praça da Cidade?

ANA - No Centro. Você não conhece?

GERALDA - Não saio muito do meu bairro.

RAIMUNDO - Continua lendo.

ANA - "Vocês serão os responsáveis por fazer a produção executiva dessa apresentação. Terão que cuidar do transporte do cenário e da banda, incluindo a adequação de palco para a montagem de som, luz e cenografia"

RAIMUNDO - Era tudo o que eu queria. Algo para movimentar a minha vida.

GERALDA - Eu não estou entendendo.

ANA - É muito trabalho. Mas, está interessante!

RAIMUNDO - O que mais tem dentro do envelope?

ANA - Tem o planejamento detalhado com um CD e um pen-drive.

GERALDA - Deve ser um pen-drive com imagens.

ANA - Eu trouxe o computador. Vamos dar uma olhada.

GERALDA - Tem tudo o que precisamos para conhecer a banda e o trabalho.

RAIMUNDO - Agora eu vou descobrir se é possível viver como produtor cultural.

GERALDA - Isso eu também quero saber. Na aula de produção, fico ouvindo a professora falar e me encanto. Mas, ela diz que é difícil ganhar dinheiro. 
ANA - Concordo! Estamos no lugar certo para descobrir isso. Eu também conheci um grupo de teatro maravilhoso, só com atores muito bons. Mas, ficavam sem grana. Tinham que investir no grupo, realizando outras atividades ou exercendo outras profissões.

Passando de mesa em mesa, Antônio se aproximou de onde os jovens estavam. Uma mulher o acompanhava. Ela estava na reunião desde o início e fazia parte do time de pessoas que trabalhavam na empresa. Eles deixaram a mesa de Ana, Raimundo e Garalda por ultimo.

ANTÔNIO - Bom dia. Muito prazer em conhecê-los. Esta é Clarice que trabalha como coordenadora de produção desde a primeira edição do FPVerão. Ela teve a ideia de trazer novas pessoas. Se vocês estão aqui, agora, é graças a ela. Já leram tudo?

ANA - Ainda não finalizamos.

ANTÔNIO - Clarice pode explicar melhor sobre essa atividade.

CLARICE - Vocês são uma aposta dessa empresa. Nunca integramos pessoas que não tivessem muita experiência em gestão cultural e não sabemos o que vai acontecer nessa experiência. Estou sendo muito sincera porque precisamos saber onde estamos pisando.

ANA - Fico muito honrada e feliz de estar nesse grupo. De fato, a experiência do grupo é...

RAIMUNDO - Acham que podemos fazer sozinhos?

CLARICE - Calma. Vocês não estão sozinhos. Não estamos jogando vocês aos leões. Estamos juntos nesse trabalho e vamos dar todo suporte. Vocês serão meus assistentes. Já foi feito um planejamento. As informações de que vocês precisam estão nesse envelope. Vocês vão executar o que está descrito. Se acontecer algum imprevisto, vamos resolver juntos.

RAIMUNDO - Uau!

ANA - A senhora não vai se arrepender.

ANTÔNIO - Espero que não. Vocês vão ler atentamente o planejamento. Qualquer alteração que acharem necessária tem que estar argumentada no planejamento. Algumas dúvidas podem surgir e vocês devem prometer que não vão sair daqui hoje com elas. Qualquer dúvida, por menor que seja, deve ser resolvida. Perguntem mais de uma vez, se achar necessário. Não alimentem a mente de vocês com dúvidas.

ANA - O planejamento pode ser mudado?

CLARICE - Um planejamento é um organismo vivo que pode ser modificado, desde que justificado. Se não houver razões para mudanças, ele deve ser seguido a risca.

ANTÔNIO - Eu sou um entusiasta de novos caminhos. Acho que as rotinas tem prazo de validade. O ser humano e o mundo são dinâmicos. Não me importo de abrir mão de algo se uma ideia melhor me for apresentada. Mas, deve ser uma ideia consciente, pensada, fundamentada. Uma ideia que seja capaz de melhorar o trabalho e seus resultados. Entendem? RAIMUNDO - Completamente.

CLARICE - Mudar por mudar ou mudar somente para queimar etapas, não vale a pena, pode apostar.

GERALDA - Todos os chefes são assim?

ANTÔNIO - Infelizmente não, Geralda. O ambiente organizacional ainda tem muita dificuldade de oferecer um protagonismo ao funcionário. Por isso, aproveitem duplamente. É preciso que se diga que não sou de fazer escândalo. Não saio gritando ou humilhando funcionários na frente de todos. Não causo constrangimento. Mas, sei cobrar quando necessário. RAIMUNDO - E é bem objetivo!

ANTÔNIO - Melhor assim, não é? Quando sabemos as regras do jogo, jogamos bem melhor. 
Naquela noite, todos dormiram com uma sensação de que uma nova vida estava surgindo. Ninguém seria poupado. Todos iriam crescer.

\subsection{O Imprevisto Começa}

Quando uma edição do FPVerão termina, começa um outro tipo de trabalho: a préprodução da edição seguinte. Seis meses antes da realização, toda a programação já fica definida. Esse ano, havia acontecido uma situação adversa. A banda de rock Cantos do Destino entrou na programação porque a banda Ratos em Fúria foi processada por um antigo integrante que não permitiu usar o nome da banda até o julgamento da causa. A reunião de alinhamento de equipe que acontece dois meses antes já estava marcada. Esse problema deveria ser resolvido com antecedência.

Em dois dias, Antônio e sua equipe, contrataram a banda Cantos do Destino e formaram uma equipe de estagiários que cuidaria do caso sob a supervisão de Clarice. Por causa dessa contratação relâmpago, alguns pontos do contrato não estavam finalizados e o setor jurídico foi acionado. O material de divulgação deveria ser entregue na quarta-feira. Mas, na segunda-feira, o jurídico ainda não tinha entregado o contrato. Clarice entrou na sala onde estavam Ana, Geralda e Raimundo.

CLARICE - Atenção, por favor. Precisamos que o jurídico nos entregue o contrato da banda. Não podemos iniciar a divulgação na quarta-feira sem que esse contrato esteja assinado. Já falei com o jurídico duas vezes e me disseram que estão resolvendo. Alguém precisa ir até lá para garantir que esse negócio ande mais rápido.

GERALDA - Acelerar o trabalho do setor jurídico? Como?

CLARICE - É o vocês precisam descobrir.

ANA - Vamos até lá para ver o que é possível ser feito.

RAIMUNDO - Devemos ir todos juntos?

CLARICE - Vocês é que devem avaliar. Vão todos?

ANA - Vamos eu e Geralda. Raimundo pode ficar para terminar de verificar os horários dos vôos e do translado dos artistas.

GERALDA - Então, aproveita para resolver a questão da bagagem. Você está copiado no email.

CLARICE - Eu vou ligar para o Dr. Marcos e avisar que irão lá. Me mantenham informada. Olhem bem pra mim: por mais que não saibam o que fazer, não deixem transparecer no rosto. Outra coisa: quando estiverem nervosos, respirem mais lentamente para não acelerar o batimento cardíaco. Dessa forma acelerada, o corpo todo descompensa. Antes de qualquer coisa, vem o querer. Queiram resolver. Acreditem nisso.

Ana e Geralda foram até lá e conseguiram descobrir o que estava acontecendo. A banda seria paga através do patrocínio dado pelo Governo do Estado, que tinha uma planilha de execução orçamentária com o nome da outra banda que teve o contrato cancelado. Eles não estavam conseguindo que a Secretaria de Cultura aprovasse a mudança do nome da banda. Então, de lá foram na Secretaria de Cultura.

ANÍBAL - Boa tarde. Meu nome é Aníbal. Sou gerente de patrocínios. Vocês querem falar comigo? Em que posso ajudar? 
ANA - Somos produtoras da CoC e estamos com uma pendência para o pagamento de uma das bandas que vão fazer parte do FPVerão. É um evento patrocinado pela Secretaria de Cultura. ANÍBAL - Estou ao dispor.

GERALDA - (Mostrando um documento) Temos esse plano de execução aprovado por vocês. No entanto, a banda Ratos cancelou o contrato e precisamos substituí-los pela banda Cantos do Destino.

ANÍBAL - Não tem problema. Me enviem outro plano que assino na hora. Sou eu que faço isso.

ANA - Nosso setor jurídico já enviou o novo plano há mais de uma semana. Veja esta cópia com a data de recebimento.

GERALDA - Precisamos dessa liberação com urgência, pois pode prejudicar nossa estratégia de divulgação.

ANÍBAL - Pela data, esse documento deve estar aqui na minha mesa. (Começa a procurar) Ah. Achei. Realmente. (Enquanto assina) Peço desculpas, mas é muita demanda para uma pessoa só. Eu preciso de equipe. Já falei isso milhões de vezes.

Agradeceram e se despediram. Correram para levar o documento assinado para o setor jurídico. Em seguida, enviaram para a banda Cantos do Destino com as cláusulas de pagamento ajustadas. Graças ao bom relacionamento com a produtora da banda, foi possível fazer um pedido especial.

RAIMUNDO - (Ao telefone) Acabei de mandar o contrato com as alterações por e-mail. Vocês precisam enviar esse contrato hoje ainda, se não vai ficar difícil incluir a banda no plano de divulgação.

PRODUTOR DA BANDA - (Ao telefone) Conta com a gente. Vou mostrar agora para o advogado e já te envio.

RAIMUNDO - (Ao telefone) Eu quero encher aquele lugar com muito público. Mas, para que isso aconteça precisamos divulgar. Me ajuda que eu te ajudo.

PRODUTOR DA BANDA - (Ao telefone) Acabei de receber. Te envio assinado ainda hoje. Pode ser assinatura eletrônica?

RAIMUNDO - Pode sim. Quando vier, você me entrega o original.

(Ao final do dia, os três jovens se encontram com Antônio e Clarice para narrar como tudo aconteceu)

ANTÔNIO - Parabéns! Problema resolvido em tempo hábil e com louvor.

CLARICE - Percebo que a autonomia já esta plantada dentro de vocês. Ótima noticia!

\subsection{O Imprevisto Continua}

Uma chuva muito forte atrasou em dois dias a montagem do palco. Este é o tipo de problema que não tem o que fazer. Contra a natureza não tem como lutar. Importante lembrar que o planejamento foi feito levando em consideração a previsão meteorológica.

Passada a tempestade, a montagem estava acontecendo em tempo recorde e outras contratações tiveram que ser feitas de forma emergencial. Esta ação teve um impacto grande na logística. Raimundo era o único que estava no local do festival, gerenciando os transportes, alimentação e entrada e saída de caminhões com equipamentos. Ana e Geralda estavam no escritório separando material promocional que precisava ser distribuído com urgência. 
Quando o caminhão do cenário chegou, Raimundo ficou desesperado. Era uma carreta enorme, que não passava pelo portão de entrada de material. O portão permitia a passagem de caminhões de seis metros, no máximo. O caminhão que chegou tinha 9 metros. Raimundo ligou para Ana, desesperado.

ANA - Raimundo... Calma... Não estou entendendo... De que caminhão você está falando? RAIMUNDO - O caminhão do cenário. Não passa pela porta. Não sei o que fazer.

ANA - Calma Raimundo. Não vamos entrar em desespero.

GERALDA - (com um telefone na mão) Rosa quer falar com você (percebe que Ana esta com uma cara preocupada). Ai, o que foi? Que cara é essa?

ANA - Raimundo, calma. Fala com Geralda que eu vou atender Rosa e falo contigo em seguida. (Ana se afasta e deixa Geralda e Antônio conversando). Oi, Rosa. Tudo bem? Sim, te liguei. O tom de verde do banner está errado. Precisa ver o tom certo que está descrito no contrato. Eu já mandei para o seu e-mail... Ótimo... Se você me enviar até 15:00 podemos aprovar, ainda hoje, com o patrocinador e produzir... Perfeito. Fico no seu aguardo. (Desliga o telefone e percebe que Geralda e Antônio estão no telefone aos berros um com o outro).

ANA - Me da esse telefone, Geralda. (Ela pega o telefone da mão de Geralda e fala com Antônio de uma forma que os dois escutam). Já temos problemas demais para ainda ter que aguentar o descontrole de vocês. Desliga o telefone. Daqui a pouco a gente conversa.

GERALDA - E agora? E esse caminhão? Como vamos resolver? Não temos como resolver isso. Não podemos quebrar a parede do palco e nem aumentar o portão.

ANA - Nervosa desse jeito não vai conseguir pensar.

GERALDA - E calma desse jeito, eu não consigo ficar.

ANA - Vamos pensar. Se perder o controle, tudo fica pior. Se o caminhão não entra por um lugar, podemos ver se ele entra por outro. Vamos tentar algo. Precisamos ir pra lá e tentar resolver.

O nervosismo estava instalado. Clarice não estava no local e isso os deixava mais nervosos do que de costume. O que ela faria? Qual seria o primeiro passo? Por que ela não tinha chegado? Todos estavam pensando nisso, mesmo precisassem se concentrar exclusivamente no caminhão. Nesse momento, Antônio entra na sala com uma cara muito séria, que elas nunca tinham visto antes.

ANTÔNIO - Preciso falar com vocês. Aconteceu um acidente.

Antônio disse que Clarice tinha sido atropelada e estava no hospital. Não havia risco de vida, mas tinha quebrado a perna, algumas costelas e estava muito nervosa. Ele comentou que estava vindo do hospital. Clarice tinha afirmado que os três jovens tinham completa condição de levar adiante o trabalho, pois o mais difícil já tinha sido feito.

ANA - Não podemos decepcionar a Clarice. Precisamos continuar.

Raimundo liga para Ana.

RAIMUNDO (Ao telefone) - Encontrou alguma solução? O que eu faço?

ANA - Clarice foi atropelada e está no hospital.

RAIMUNDO - O que?

ANA - É sério. Estamos aqui sem saber o que fazer. Antônio foi no hospital, falou com ela e disse que temos total condição de continuar o trabalho sem ela. 
RAIMUNDO - O que?

Geralda pega o telefone da mão de Ana.

GERALDA - Eu quero desistir. Eu estou nervosa.

RAIMUNDO - Respire. Respire, lentamente. Confiamos em tudo o que ela disse até agora. Por que não vamos confiar agora?

GERALDA - Será?

RAIMUNDO - Ela está com um problema e nós não seremos mais um. Vamos encontrar soluções. Continuem pensando daí que eu vou ganhando tempo daqui.

Desligam o telefone e se olham profundamente. Um tempo de silêncio se instala. Geralda é a primeira a falar.

GERALDA - Eu acho que precisamos falar com Antônio.

ANA - Eu acho que precisamos tentar resolver primeiro.

GERALDA - Eu vou falar com Antônio.

(Toca o telefone de Ana. É Raimundo)

ANA - Oi Raimundo... Ótimo... Tudo bem... Vamos ao seu encontro. Já estamos quase acabando de separar o material promocional. Aproveitamos e levamos tudo de uma vez. (Desliga)

GERALDA - Ele resolveu?

ANA - Não. Mas, conseguiu colocar o caminhão estacionado em um lugar da praça para ganharmos tempo.

GERALDA - Eu vou falar com Antônio agora.

ANA - Geralda, espera...

Geralda entra na sala de Antônio que está de cabeça baixa, escrevendo alguma coisa. Quando vê Antônio, fica em silêncio. Está paralisada.

ANTÔNIO - Pode falar Geralda.

GERALDA - O cenário não entra pela porta de serviço. O caminhão não passa pelo portão. Ele está estacionado. Raimundo estacionou.

ANTÔNIO - Raimundo dirige caminhão?

GERALDA - Não. Raimundo organizou o caminhão. A rua é pequena e o motorista não cabe. Clarice no hospital e tudo acontecendo...

ANTÔNIO - Geralda, respire fundo. Eu não estou entendendo nada. Aconteceu um problema e vocês precisam resolver. Se você não voltar a respirar normalmente não vai conseguir se concentrar em nada.

GERALDA - O caminhão com o cenário chegou. Mas, é um caminhão gigante e não passa pela porta do Palco do Rock.

ANTÔNIO - Vocês não tinham a dimensão do caminhão antes dele chegar?

ANA - (Entrando na sala) Sim, tínhamos. A empresa teve um problema e mudou o caminhão sem nos consultar. Acho que não imaginavam que daria problema.

ANTÔNIO - Então, agora vocês precisam resolver. Só isso. Ir até o local e encontrar uma solução para o problema.

GERALDA - Eu não consigo pensar nem de por onde começar. 
ANTÔNIO - Pelo princípio, pela presença e pela imaginação. Imagine que você tem uma geladeira grande e que ela não entra pela porta da casa nova. O que você faz?

GERALDA - Vendo a geladeira.

ANTÔNIO - E se não puder vender a geladeira?

GERALDA - Vejo se da para entrar por outros lugares.

ANTÔNIO - Você já viu se da para entrar com o cenário por outros lugares?

GERALDA - Não.

ANTÔNIO - Imagine que você tinha planejado duas pessoas para te ajudar nessa manobra da geladeira. Mas, quando você percebeu que ia dar mais trabalho do que pensava, calculou que só aquelas duas pessoas não iam dar conta. O que você faz?

GERALDA - Chamo mais gente pra ajudar.

ANTÔNIO - É isso. Tem que pensar. Não pode se desesperar. Se não entra por um lugar, tenta por outro. Se a atual quantidade de pessoas não conseguem fazer o serviço, provável que tenhamos que envolver outras. Mas, tem que tentar alguma coisa. Tem que estar lá e resolver.

GERALDA - (Meio sem graça, olhando para Ana) Certo. Vamos acabar de separar o material e vamos.

ANA - Podemos ir. Eu já terminei de separar.

ANTÔNIO - Lembre-se: não reclame. Abrace o problema, que ele mesmo te mostra a solução. Eu sei que a ausência de Clarice causa instabilidade. Mas, se ela me disse que vocês são capazes, eu acredito. Falta vocês acreditarem.

Quando as jovens chegaram ao local, Raimundo já sabia o que fazer. Conseguiu a solução conversando com o motorista que estava louco para resolver e pegar a estrada. Ele não gostava muito de ficar na cidade. Contratou quatro carregadores da empresa de som que tinham acabado de descarregar. Esses carregadores iriam pegar o material do cenário no caminhão estacionado na rua e trazer até o palco. Seria preciso umas 15 viagens para trazer tudo, percorrendo uma distância de 200 metros, aproximadamente. Eles tinham um carrinho da empresa de som que facilitaria o serviço. Cada um recebeu 50 reais em dinheiro, logo após de descarregar. Quando estava pagando, Geralda lembrou de uma coisa importante.

GERALDA - Vamos deixar combinado com eles para a desmontagem?

ANA - Excelente ideia. Vamos sim.

RAIMUNDO - Claro. Eles já sabem o trabalho. Já conhecem o percurso e já conhecem o material.

ANA - Parece que o caminhão e o cenário estão resolvidos. Mas, temos outro assunto para conversar.

RAIMUNDO - O que?

ANA - Precisamos falar do descontrole de vocês dois.

GERALDA - Você vai contar pro Antônio?

ANA - Preciso?

RAIMUNDO - Geralda, eu quero te pedir desculpas. Não sei o que aconteceu. Eu sou acostumado a trabalhar sobre pressão. No hospital, vivo momentos difíceis. Não sei o que aconteceu...

GERALDA - Eu que te devo desculpas, Raimundo. (Geralda tem um descontrole e começa a chorar na frente dos amigos). Eu tenho esse problema. Preciso melhorar. Minha mãe grita o dia todo, para qualquer coisa. Acho que acabei aprendendo a ser desse jeito. Esse convívio esta tão diferente. Estou tendo a oportunidade única de trabalhar com pessoas que vivem momentos 
delicados e resolvem tudo na maior elegância, sem gritaria, sem falta de educação, sem ofensas... eu não quero estragar tudo. Preciso da ajuda de vocês.

ANA - Eu não sou melhor que você, Geralda. Também estou com medo. Não quero errar. Mas, precisamos ter calma. Temos que nos apoiar.

RAIMUNDO - Que bom que tenho vocês duas nesse trabalho. Obrigado!

(Ana e Raimundo começam a chorar junto com Geralda. Os três vivem uma grande catarse)

Aquele dia foi um divisor de águas na descoberta de potencialidades daquele trio. Ficaram mais unidos e mais fortes dentro do coletivo e individualmente. Sentiam-se como se tivessem subido um degrau no desenvolvimento profissional.

\subsection{O Imprevisto Persiste}

Tudo certo com a montagem. O espetáculo teria início em menos de seis horas. $\mathrm{O}$ frio na barriga era constante, mesmo diante daquela calmaria. Tudo estava ocorrendo no horário planejado. Ainda assim, existia uma tensão. Muito natural, afinal, em um trabalho como esse, a linha entre o sucesso e o fracasso é tênue.

Não demorou para aparecer mais um problema bem delicado. Antônio chegou de surpresa para ver se estava tudo certo. Ele fez a mesma coisa nos outros sete espaços que também estavam sendo montados. Naquele dia, aconteceria ao mesmo tempo, três shows, duas peças de teatro, uma apresentação de circo e duas aberturas de exposição com sarau de poesia.

Ao passar pelo camarim da banda e ver o figurino que estava pendurado, ficou preocupado. O principal patrocinador do festival era uma empresa de telefonia que tinha uma marca roxa. Por isso, toda a decoração tinha essa cor de forma mais destacada. A concorrência direta era outra empresa de telefonia que tinha o amarelo como cor principal e o figurino da banda tinha o amarelo como cor predominante.

ANTÔNIO - Temos uma questão delicada para ser resolvida. Estou com medo de um mal estar com os patrocinadores por causa das roupas amarelas.

ANA - O que podemos fazer? Pedir à banda para trocar o figurino?

ANTÔNIO - Sim. Aconselho a dar a dimensão do problema antes de pedir que troquem o figurino. É um mal estar que envolve muitas pessoas. A hora de fazer alguma coisa é agora, enquanto ainda podemos.

RAIMUNDO - Mas imagine. A banda contrata um figurinista, desenha um figurino, manda costurar, experimenta e na hora de usar não podem?

GERALDA - Sim. Imprevistos acontecem e precisamos aprender a lidar com eles. De qualquer forma, eles não vão perder o figurino. Apenas, vão usar em outra ocasião. Eu tenho uma ideia. E se oferecermos outras roupas para eles?

ANA - Temos muitas lojas como apoiadoras do nosso evento. Vamos a essas lojas com a figurinista para escolher a vontade .

RAIMUNDO - Ainda aumentamos a visibilidade para as lojas que fornecerem, pois serão citadas no palco.

ANA - Preciso passar no hotel para ver a sala da coletiva de imprensa amanhã, depois dos eventos de hoje.

RAIMUNDO - Vou ligar para a figurinista, Valéria. Converso sobre essa situação que estamos passando. 
GERALDA - Vou com você, Ana. Fico no hotel, vendo a sala e resolvendo tudo. Enquanto isso, Raimundo leva a figurinista no Shopping para ver as roupas. Temos somente seis horas até o show começar. Será que vai dar tempo?

ANTÔNIO - Vocês tem tempo de sobra. Boa sorte!

A conversa com a figurinista foi ótima e o passeio no shopping também. Tudo parecia funcionar bem. O show teve início e a plateia estava lotada.

\subsection{O Imprevisto Enlouquece}

A previsão era de que, ao término, Ana acompanharia a banda até o restaurante para jantar. Raimundo acompanharia a desmontagem do palco que tinha cenário, luz e som. Geralda faria o fechamento de borderoux com a casa, verificando quantos ingressos tinham sido vendidos e quantos convidados apareceram. Entretanto, um incidente, nos instantes finais, mudou toda a rotina que estava programada.

O cantor da banda subiu em uma caixa de som para mandar um beijo para a plateia, que o tinha deixado emocionado. Quando subiu, escorregou e caiu no chão. Bateu com a cabeça e desmaiou. Raimundo chamou os paramédicos pelo rádio, imediatamente. Toda a banda correu para o local do cantor caído. A plateia ficou em silêncio absoluto. Três mil pessoas em silêncio. Ana pegou o microfone, no reflexo, e fez uma comunicação para a plateia.

ANA - Boa noite. Meu nome é Ana. Sou da equipe de produção e preciso da ajuda de vocês. Como viram, o nosso querido Dino Pauleira caiu, bateu a cabeça e já está sendo atendido pelos médicos. Não sabemos a extensão da situação, mas deixaremos todos informados com boletins periódicos, no site do evento. Vamos sair devagar e confiantes de que tudo vai dar certo. Eu gostaria de pedir uma salva de palmas para esta banda maravilhosa e dizer que estamos juntos para resolver tudo o que aparecer.

Todos aplaudiram e Ana sentiu uma confiança que jamais sentiu em sua vida. Todos estavam mais fortes. Raimundo já tinha acionado a ambulância que estava no aguardo. Acompanhou o vocalista até o hospital, onde ficou todo o tempo. Geralda levou uma mesa para o palco. Fez o fechamento do borderoux enquanto acompanhava a desmontagem dos equipamentos. Ana levou a banda para o hotel, onde uns jantaram e outros não. Ela ficou o resto da noite gerenciando informações do hospital, da produção e da família para a imprensa. Usaram a sala que estava pronta para a coletiva. Pela primeira vez, por conta do acidente, o mundo teve maior conhecimento do FPVerão.

O Festival continuou seus outros dias de atividades.

\subsection{O Imprevisto Qualifica}

Chega o dia da avaliação final.

ANTÔNIO - Vamos iniciar mais uma reunião de avaliação. Estou feliz por chegar a finalização do FPVerão com muitos pontos positivos. Vivenciamos uma situação atípica e, pela primeira vez, Clarice não estava por perto. Devo dizer que ela está bem melhor e já deixou o hospital. Está em casa e espera a visita de todos. Mesmo não estando aqui, agora, ela me surpreendeu. 
Durante o pouco tempo que esteve com sua equipe, conseguiu criar as condições necessárias para que confiassem no potencial e na capacidade de resolver problemas. Gostaria que Raimundo, Ana e Geralda fossem os primeiros a comentar o que eles viveram e o que eles aprenderam com esta experiência.

ANA - (Os estudantes constroem e narram o aprendizado de Ana)

GERALDA - (Os estudantes constroem e narram o aprendizado de Geralda)

RAIMUNDO - (Os estudantes constroem e narram o aprendizado de Raimundo)

\section{Notas de Ensino}

\subsection{Sinopse}

Estudantes que buscam se tornar gestores se confrontam com a importância da improvisação organizacional ao estagiarem em uma organização de eventos culturais. Como enfrentam muitas situações de imprevisto dentro de um planejamento muito bem realizado, refletem sobre como esse estado de improvisação é estratégico para se tornarem gestores competentes. Eles observam o gestor dentro de uma experiência de gestão em uma organização cultural. Observam suas competências de improvisar, assegurando o sucesso contínuo do evento. $\mathrm{O}$ choque foi grande entre o que cada um pensava sobre ser administrador e o que aprendeu na pratica neste festival. A tomada de consciência e a aprendizagem não foram realizadas sem um profundo incômodo por parte dos jovens estudantes.

\subsection{Objetivos Educacionais}

O caso para ensino permite alcançar os seguintes objetivos educacionais:

- Entender a importância crucial da improvisação para as organizações e gestores contemporâneos.

- Refletir sobre o papel da imperfeição, cooperação e competição para a prática da improvisação organizacional.

- Identificar e discutir sobre desafios e competências de improvisação para gestores.

\subsection{Fonte de Dados}

O caso é construído a partir da observação participante da primeira autora deste trabalho em processos de organização e gestão de vários eventos culturais no Brasil durante 25 anos. Os eventos observados foram: Festival do Teatro Brasileiro, Viva Dança Festival, MID Movimento Internacional de Dança, FIAC - Festival Internacional de Artes Cênicas, Mercado Cultural, Via Bahia Festival, festivais internacionais em Cadiz (Espanha), Ajudá (Benin/África) e na Bielorrússia (Rússia). A observação foi sistemática, prolongada e participante. Foi objeto de anotações periódicas e detalhadas sobre descrições e reflexões, envolvendo os processos de gestão e organização de todos que trabalhavam nos eventos. A pesquisadora trabalhou, em 
alguns eventos, como gestora, como responsável pela área técnica, como produtora ou coordenadora de produção, como artista. As observações contabilizam uma média total de 3 mil horas. As informações oriundas das observações foram contextualizadas a partir de documentos produzidos em cada evento.

Outra fonte importante de dados provém de observações, entrevistas e documentos no contexto de um experiência de ensino na graduação em Administração da Universidade Federal da Bahia durante 5 semestres. Em um componente curricular sobre gestão cultural, a turma organizou e administrou um festival cultural a medida que ia praticando, em paralelo, exercícios de improvisação teatral. Durante todo esse processo de organização e administração, foram feitas entrevistas, observações e documentação. Esse material foi abundante em termos de experiências de improvisação organizacional.

As anotações de observações, documentos e entrevistas foram analisadas a partir da abordagem de análise de narrativas. Teve como eixo temático as situações de improvisação organizacional que se mostravam mais típicas, representativas e ricas em termos de detalhes descritivos e impactos sobre a gestão. A observação foi a fonte primária para a análise de narrativas sobre a improvisação organizacional. Os documentos e entrevistas ajudaram a melhor contextualizar e caracterizar as narrativas escolhidas.

\subsection{Uso Pedagógico Sugerido}

O caso para ensino é adequado ao ensino em diversas disciplinas do curso de graduação (Liderança, Empreendedorismo, Competências Gerenciais, Práticas de Gestão, Teorias de Administração, Estudos Organizacionais) e pós-graduação (principalmente, mestrados profissionais nas disciplinas de liderança e competências de gestão) em Administração, que desejem discutir questões associadas a competências de gestão. $\mathrm{O}$ caso para ensino contribui para enriquecer o ensino teórico e estimular o pensamento crítico dos estudantes.

Para o uso do caso em sala de aula, sugerimos um conjunto de atividades, organizadas em dois momentos. Estes dois momentos podem ser adaptados para dois dias ou para uma mesma aula em dois momentos. O que pode variar é o tempo reservado para a execução de cada etapa. O trabalho feito em dois dias tem trazido resultados bem mais aprofundados, uma vez que a reflexão fora do ambiente de sala de aula ajuda a amadurecer e enriquecer a reflexão e consolidação da aprendizagem.

\section{PRIMEIRO MOMENTO}

- Dividir a turma em três grupos de estudantes para a leitura do caso. Cada grupo será o representante de cada um dos personagens principais: Ana (Grupo A), Geralda (Grupo B) e Raimundo (Grupo C).

- Ler a parte do caso, onde cada grupo irá contribuir como atores. O Grupo A vai ler os personagens de Ana e Antônio. O Grupo B vai ler os personagens de Geralda e Clarice. O Grupo C vai ler os personagens Raimundo, Aníbal e Produtor da Banda. O narrador deve ser lido pelo(a) professor(a). 
- Instruir os grupos para criarem uma fala final para definir a aprendizagem de seu personagem (Ana, Geralda ou Raimundo) na reunião de avaliação. Esta fala será apresentada para a turma, durante a leitura do caso.

- Solicitar que os estudantes leiam, previamente, os textos de Weick (2002), Cunha e Cunha (2000) e Kirschbaum et al. (2014), para a realização das próximas atividades.

\section{SEGUNDO MOMENTO}

- Dividir a turma em três grupos de estudantes, preferencialmente, formados por pessoas diferentes dos grupos da aula anterior.

- Atribuir o texto de Weick (2002) ao Grupo A e solicitar uma resposta para a Questão \#1, a ser apresentada para a turma.

- Atribuir o texto de Cunha e Cunha (2000) ao Grupo B e solicitar uma resposta para a Questão \#2, a ser apresentada para a turma.

- Atribuir o texto de Kirschbaum et al. (2014) ao Grupo C e solicitar uma resposta para a Questão \#3, a ser apresentada para a turma.

- Solicitar que cada grupo apresente a resposta que elaborou para sua questão. Em seguida, estudantes e professor(a) podem comentar e debater.

- Solicitar que cada grupo formule uma resposta para a Questão \#4, levando em consideração os textos estudados e o debate sobre as respostas anteriores.

- Solicitar que cada grupo apresente a resposta que elaborou para a Questão \#4, com discussões realizadas no final de todas as apresentações.

\subsection{Questões para Discussão}

Questão \#1 - Imperfeição, Improvisação e Gestores

Qual é o papel da imperfeição na improvisação organizacional no caso estudado com base em Weick (2002)? Que desafios a imperfeição traz para os gestores-improvisadores?

Questão \#2 - Organização Improvisadora e Competências de Gestão

O que caracteriza uma organização improvisadora e as competências de seus gestores no caso estudado com base em Cunha e Cunha (2000)?

Questão \#3 - Cooperação e Competição na Improvisação Organizacional

Quais são os papeis e desafios de cooperação e de competição na improvisação organizacional no caso estudado com base em Kirschbaum et al. (2014)? Como os gestores podem se formar para enfrentar esses desafios?

Questão \#4 - Importância da Improvisação para Gestores

Qual é a importância da improvisação para gestores no caso estudado com base em Weick (2002), Cunha e Cunha (2000) e Kirschbaum et al. (2014)?

\subsection{Análise e Discussão do Caso}




\subsubsection{Questão \#1 - Imperfeição, Improvisação e Gestores}

Qual é o papel da imperfeição na improvisação organizacional no caso estudado com base em Weick (2002)? Que desafios a imperfeição traz para os gestores-improvisadores?

Weick (2002) trás a ideia de imperfeição em oposição ao desejo de perfeição que persegue as organizações. Se tivermos quinze pessoas em uma sala realizando o mesmo serviço teremos quinze possibilidades de executar aquela atividade, embora estejam realizando as mesmas ações. As atividades são executadas por seres humanos que são passiveis de mudanças e transformações constantes. Quinze pessoas em um espaço de trabalho constitui um organismo vivo que compreende etapas distintas de funcionamento e que precisa de cuidados. Dentro de um organismo vivo que pressupõe um funcionamento é possível que algumas ações não alcancem a perfeição desejada, mas que cumpre a mesma função e, muitas vezes, ate apontem para caminhos estéticos diferentes. Outras vezes, o erro pode ser utilizado como ação reveladora de uma rotina que não se apresenta eficiente. Um resultado positivo, seja lá qual for, é fruto de uma sequencia de ações, que podem ser traduzidas por etapas. Essas etapas tendem a ser ajustadas a medida que o processo seja repetido. Os vínculos entre o sujeito e a atividade são criados na repetição de procedimentos, o que pode levar a caminhos interessantes.

O tempo e a auto-observação são aliados na execução de uma atividade. Não devemos fugir dos erros pois podem ser capazes de gerar uma reflexão sobre os procedimentos, inclusive apontando para o momento de serem modificados. Somos imperfeitos e com o tempo vamos ajustando a nossa existência. Aceitar a imperfeição é aceitar o processo de aprendizagem. Sem falar que, por medo do erro, boas ideias não são ditas. Aceitar a imperfeição como parte do processo de aprendizagem é libertador do ponto de vista da coragem de arriscar. É o primeiro passo para não ter medo de errar. A imperfeição faz parte da improvisação, tanto quanto a inovação e a renovação. Não ter medo do erro, do inacabado ou do imperfeito confere uma liberdade de associações que abrem caminho para a criatividade. $\mathrm{O}$ ambiente organizacional, que exige respostas rápidas às lacunas que surgem, é rico em imperfeições. Essa condição é o que nos aproxima da natureza humana e da desordem criada por questões da gestão. Essa condição estimula a geração de ideias e a criatividade no trabalho envolvendo tanto o coletivo quanto o individual.

A estudante de Administração (Ana), o estudante de teatro (Raimundo) e a estudante de produção cultural (Geralda), tem uma experiência de gestão cultural que modifica, definitivamente, suas vidas. Ao serem responsáveis por encontrar soluções para os problemas que se apresentam em um festival cultural - FPVerão -, aprendem mais do que as tarefas planejadas lhes exigem. O compromisso e o envolvimento foram cruciais para resolver e entender procedimentos até então desconhecidos como: acelerar a burocracia para a assinatura de um contrato, aceitar que o líder não estará presente, administrar bem o problema que aconteceu com o cenário do espetáculo, manter o controle emocional diante da adversidade, lidar de forma criativa com a troca de figurino em tempo recorde e administrar adequadamente um acidente que envolveu o vocalista da banda.

Este é um desafio para gestores. Aceitar a imperfeição não significa diminuição de critérios de eficiência. A imperfeição surge como resultado de algo que intencionava ser perfeito. O desejo tem que ser o de acertar sempre. Ao entrar no jogo, é preciso ter o desejo e a vontade de ganhar. $\mathrm{O}$ ganhar pode ser compartilhado com muitas pessoas e muitos setores organizacionais, pois, diferente do esporte, aqui todos podem ganhar. 


\subsubsection{Questão \#2 - Organização Improvisadora e Competências de Gestão}

O que caracteriza uma organização improvisadora e as competências de seus gestores no caso estudado com base em Cunha e Cunha (2000)?

Cunha e Cunha (2000) apontam como competência do gestor, a flexibilidade e a capacidade de manter a calma diante de uma situação adversa. A organização improvisadora se caracteriza por aceitar e estimular um gestor com habilidade de improvisação organizacional. É uma organização que não se opõe a abrir mão de uma decisão quando uma situação nova se impõe, interferindo diretamente no planejamento. Trata-se de um estado onde a emoção se instala, provocando desordens mentais equivalentes ao ambiente externo.

O treino da improvisação desperta a capacidade de manter-se ativo mesmo diante de elevados níveis de incerteza. Esse exercício aumenta a capacidade de aprendizagem, dando à vulnerabilidade o status de companheira, o que torna possível uma melhor observação dos seus aspectos. Estes momentos exigem decisões em tempo real, podendo revelar líderes e novas formas de olhar para o problema como podemos ver em Ana, que consegue manter o equilíbrio através de um controle emocional de aceitar as questões que estavam acontecendo, e de se relacionar com elas de uma forma positiva tentando resolver uma coisa de cada vez sem se deixar levar pela ansiedade de prever o futuro. Acreditar que é possível é o primeiro passo para ser possível e rapidamente ela vira uma liderança para os companheiros. Quanto melhor for o planejamento, melhor será a improvisação, que possui períodos curtos de estabilidade e alto nível de incerteza. Tem também dinamismo, complexidade sistêmica, heterogeneidade e velocidade de inovação. Ou seja, constatamos uma boa oportunidade de desaprender algo e abrir caminho para fazer de outra forma.

A flexibilidade e manutenção da calma também podem estar associadas a abrir mão de um planejamento pré-existente. Um bom exemplo é quando Ana, Geralda e Raimundo descobrem que Clarice não estará mais com eles, diariamente. Cada um aceitou a situação em momentos diferentes. Existe uma resistência, no corpo, que quando é quebrada, provoca alívio e ideias. Uma organização é improvisadora quando seu componente mais importante são as pessoas, dotadas de capacidade de transformação. Aceitar as transformações não significa ser destituído de regras. O planejamento e os limites são fundamentais para que a improvisação se apresente como necessária e potente. Quando a liberdade de improvisar se instala na organização, o que acontece são colaboradores mais tranquilos em correr riscos e inovar. Quando Antônio se mostrou confiante na equipe, ele reforça a ideia de fazer o melhor possível. Positivar a situação, confiar, ajudar a pensar e motivar são competências de um gestor para que sua equipe fique a vontade em se envolver plenamente com a organização. Se os propósitos da organização estiverem bem estabelecidos, incluindo a liberdade de improvisar, quando for necessário, ela pode produzir momentos únicos e inovações.

\subsubsection{Questão \#3 - Cooperação e Competição na Improvisação Organizacional}

Quais são os papeis e desafios de cooperação e de competição na improvisação organizacional no caso estudado com base em Kirschbaum et al. (2014)? Como os gestores podem se formar para enfrentar esses desafios?

Kirschbaum et al. (2014) destacam a competição e a cooperação como competências da improvisação que melhoram a capacidade de gerenciamento de crises. Quando acontece de forma natural e sem maiores direcionamentos, revelam pontos de desorganização dentro da 
organização e velhas rotinas que não atendem mais as demandas da atualidade. Também podem surgir como pontes para novos procedimentos no trabalho. São competências que indicam para o treinamento e melhoria da capacidade de lidar com o momento e com suas circunstâncias ampliando a apropriação do contexto e das relações emocionais. A improvisação é natural no ser humano, assim como com sua capacidade de transformação. Pode servir para um momento de mudança de estratégia, conectando o indivíduo ao conflito existente. É uma mistura de desafio relacional, temporal e emocional que traz consigo a inovação.

$\mathrm{Na}$ história do caso, percebemos essa situação quando o ator sofre um acidente e tudo deve ser reestruturado para que as atividades possam acontecer sem atrasos. O objetivo deve estar sempre muito claro, pois vai determinar a direção da improvisação, bem como a força de seus resultados. No que tange a competição, podemos destacar que se trava uma luta contra o tempo. É preciso achar soluções em tempo real. Associar competição entre duas pessoas é simples. Mas, improvisar significa criar uma competição consigo próprio e com o outro, conseguindo potencializar características individuais que ressaem no coletivo.

A questão da competição deve ser bem debatida pois não se trata de incentivar esta pratica sem o advento da cooperação. Estimular a competição entre colegas acaba por desenhar outra forma de relação dentro das organizações, correndo o risco de que as pessoas passem a trabalhar em beneficio próprio e criem suas próprias regras. Se o trabalho de equipe e cooperação forem estimulados no ambiente de trabalho, a competição passa a ser contra o tempo e em busca da excelência. No caso estudado, vemos o quanto que os três estagiários ganharam força quando se perceberam como uma equipe. Inversamente, teríamos um resultado diferente se cada um tentasse ser herói ou resolver as questões sozinho, revelando um desejo de ser melhor do que o outro.

A formação do gestor proposta pelo caso estudado tem raízes profundas na ação do mundo prático. A maior ação formativa que os estagiários aconteceu no fervor da prática. Ter uma experiência onde as suas ações vão determinar os rumos dos acontecimentos inaugura uma nova postura diante da vida. Nessa experiência, os jovens não estavam desamparados. Foram orientados por gestores experientes. Este exercício em sala de aula pode servir de estimulo para que os estudantes realizem uma atividade sendo amparados, na organização, pelos professores. Essa atividade pode configurar uma experiência prática de ensino-aprendizagem de planejamento e de improvisação, para além do espaço da sala de aula. Neste contexto prático, a execução de um planejamento e a improvisação tornam-se uma aprendizagem preciosas.

\subsubsection{Questão \#4 - Importância da Improvisação para Gestores}

Qual é a importância da improvisação para gestores no caso estudado com base em Weick (2002), Cunha e Cunha (2000) e Kirschbaum et al. (2014)?

Os três textos trazem características que podem ser observadas no dia-a-dia das organizações e nas etapas de improvisação. Elas podem ser observadas integralmente ou seccionadas para fins didáticos. Todas as características apontadas refletem a necessidade de envolvimento, aceitação do erro, cooperação, competitividade, flexibilidade e capacidade de manter o discernimento na busca de soluções. A improvisação deve ser aceita como técnica que exige do improvisador habilidades especificas, tais como controle emocional e treinar distintas formas de enxergar o erro. Mas, o foco é sempre perceber o erro como oportunidade. Devemos ser capazes de pensar positivo ou mesmo saber transformar uma situação difícil em algo positivo. 
A habilidade relacional também tem grande impacto. Aceitar o outro e suas dimensões, sabendo como estimular suas potencialidades é uma postura imprescindível. Ter total imersão no campo de atuação faz-se necessário para que possa ser criado um repertorio de possíveis soluções, como os repentistas construíram um repertorio de rimas e o jogador de futebol internalizaram diversas jogadas. A improvisação se faz a partir da repetição de algo já enraizado, pois o corpo, na busca da transformação aponta sempre novos caminhos. Como complemento também podemos associar as características de prontidão, foco (Goleman \& Senge, 2015) e presença física (Goleman \& Senge, 2015) como necessárias para que as outras possam se desenvolver.

\section{REFERÊNCIAS}

Barrett, F. J. (2012). Yes to the Mess: Surprising Leadership Lessons from Jazz. Boston: Harvard Business School Press.

Bernstein, E. S., \& Barrett, F. J. (2011). Strategic Change and the Jazz Mindset: Exploring Practices that Enhance Dynamic Capabilities for Organizational Improvisation. Research in Organizational Change and Development, 19, 55-90.

Crossan, M., Cunha, M. P., Vera, D., \& Cunha, J. (2005). Time and organizational improvisation. Academy of Management Review, 30(1), 129-145.

Crossan, M., \& Sorrenti, M. (1997). Making sense of improvisation. Advances in Strategic Management, 14, 155-180.

Cunha, M. P. (2002). All that jazz: três aplicações do conceito de improvisação organizacional. Revista de Administração de Empresas, 42(3), 36-42.

Cunha, M. P. (2005). A arte dos improvisadores: a busca da estandardização na música e nas organizações. Organizações \& Sociedade, 12(32), 93-104.

Cunha, M. P., \& Cunha, J. V. d. (2000). Improvisação e organização. In S. B. Rodrigues \& M. P. Cunha (Eds.), Estudos organizacionais: novas perspectivas na administração de empresas - uma coletânea Luso-Brasileira. São Paulo: Editora Iglu.

Fischer, C. M., \& Amabile, T. M. (2009). Creativity, improvisation and organizations. In T. Rickards, M. A. Runco, \& S. Moger (Eds.), The Routledge Companion to Creativity. New York: Routledge.

Flach, L., \& Antonello, C. S. (2011). Improvisação e Aprendizagem nas Organizações: reflexões a partir da metáfora da improvisação no teatro e na música. In C. S. Antonello \& A. S. Godoy (Eds.), Aprendizagem Organizacional no Brasil. Porto Alegre: Bookman. 
Goleman, D., \& Senge, P. (2015). O foco triplo: uma nova abordagem para a educacão. Rio de Janeiro: Objetiva.

Hatch, M. J. (1998). Jazz as a metaphor for organizing in the 21 st century. Organization Science, 9(5), 556-557.

Hatch, M. J. (2002). Explorando os espaços vazios: jazz e estrutura organizacional. Revista de Administração de Empresas, 42(3), 19-35.

Kamoche, K. N., Cunha, M. P., \& Cunha, J. V. (Eds.). (2002). Organizational improvisation. London: Routledge.

Kirschbaum, C., Sakamoto, C., \& Vasconcelos, F. C. (2014). Conflito e improvisação por design: a metáfora do repente. Organizações \& Sociedade, 21(68), 59-78.

Miner, A. S., Bassoff, P., \& Moorman, C. (2001). Organizational Improvisation and Learning: A Field Study. Administrative Science Quarterly, 46(2), 304-337.

Montuori, A. (2003). The complexity of improvisation and the improvisation of complexity: Social science, art and creativity. Human Relations, 56(2), 237.

Radjou, N., Prabhu, J., \& Ahuja, S. (2012). A inovação do improviso: por que menos é mais na construção de riquezas e resultados. Rio de Janeiro: Elsevier.

Santos, L. A. N. d., \& Davel, E. (2015). Improvisação como competência cultural: uma autoetnografia da atividade gerencial no setor público. Revista Gestão \& Conexões, 4(1), 91-115.

Senge, P., Scharmer, C. O., Jaworski, J., \& Flowers, B. S. (2007). Presença: Propósito Humano e o Campo do Futuro. São Paulo: Cultrix.

Vera, D., \& Crossan, M. (2004). Theatrical Improvisation: Lessons for Organizations. Organization Studies, 25(5), 727-749.

Weick, K. (2002). A estética da imperfeiçao em orquestras e organizaçoes. Revista de Administração de Empresas, 42(3), 6-18.

Weick, K. E. (1998). Improvisation as a mindset for organizational analysis. Organization Science, 9(5), 543-555. 